\title{
Bosworth fracture complicated by unrecognized compartment syndrome: a case report and review of the literature
}

\author{
Jan Bartoníček ${ }^{1}$ (D) $\cdot$ Stefan Rammelt ${ }^{2}$ D $\cdot$ Karel Kostlivý $^{3}$ (D)
}

Received: 10 December 2020 / Accepted: 1 February 2021 / Published online: 17 February 2021

(c) The Author(s) 2021, corrected publication 2021

\begin{abstract}
Introduction Compartment syndrome (CS) is exceedingly rare in ankle fractures. However, the risk of CS development seems to be increased in the presence of a Bosworth fracture-dislocation (BF), a rare variant of locked dislocation of the fibula behind the tibia.

Materials and methods Here, we report the case of a 39-year old man with delayed diagnosis of CS after having sustained a $\mathrm{BF}$ and failed attempts on closed reduction. The patient developed a flexion contracture of the hallux necessitating secondary fusion.

Results At 3 years after the injury, the patient was capable of running, but had 10 degrees limitation of ankle dorsiflexion, persisting decreased sensation on the plantar surface and clawing of the lesser toes. A thorough review of the literature revealed nine cases of CS after 167 reported BF resulting in a calculated prevalence of 5.4\%.

Conclusions Given the extreme paucity of CS in malleolar fractures, CS in BF has a relatively high prevalence. Risk factors include severe dislocations, repeated attempts on closed reduction, and a long interval to definite surgery. A high index of suspicion is required because delayed diagnosis leads to lasting functional restrictions.
\end{abstract}

Keywords Ankle $\cdot$ Fracture $\cdot$ Locked dislocation $\cdot$ Compartment syndrome $\cdot$ Fasciotomy

Bosworth fracture $(\mathrm{BF})$ is a rare type of ankle fracture-dislocation, characterized by entrapment of a fibular fragment behind the posterior surface of the tibia [1]. In Weber type $\mathrm{B}$ fractures it is the proximal fragment, while in Weber type $\mathrm{C}$ it is the distal fragment that is entrapped [2]. Recent CTbased studies have shown that BF is a severe injury regularly associated with fractures of the posterior malleolus and fraught with multiple possible complications including posttraumatic arthritis [3, 4]. In addition, BF seem to be

Stefan Rammelt

bartonicek.jan@seznam.cz

1 Department of Orthopaedics, First Faculty of Medicine, Charles University and Central Military Hospital, U Vojenské Nemocnice 1200, Prague 6169 02, Czech Republic

2 University Center of Orthopaedics, Trauma and Plastic Surgery, University Hospital Carl Gustav Carus Dresden, Fetscherstrasse 74, 01307 Dresden, Germany

3 Department of Surgery of 1st Faculty of Medicine, Charles University and Thomayer Hospital, Videnska 800, Prague 4140 00, Czech Republic prone to serious acute soft tissue complications like compartment syndrome (CS), skin necrosis, ankle stiffness and neurovascular damage [5-11]. Acute CS complicating a BF has been described for the first time by Szalay and Roberts [5], in 2001, and subsequently only by few other authors with delayed diagnosis in some cases [6-11].

The purpose of this study is to raise the awareness for this problem which may be neglected at first presentation and its implications on the basis of the authors' own case and a thorough review of the literature. Over several years, we performed a literature review on Bosworth fracture-dislocations without time or language restriction [2-4]. For systematic research we used different combinations of the search terms "ankle" OR "malleolar" AND "fracture" OR "dislocation" AND "Bosworth" OR "locked dislocation" in PubMed, Medline, Google, Google Scholar, Scopus and selected textbooks until August 2020. Then, all articles pertaining to Bosworth fracture-dislocations were screened in the full text for the mention of a manifest compartment syndrome, symptoms of an impending compartment syndrome or late sequelae of a compartment syndrome. 


\section{Case report}

A 39-year-old man slipped while running in the woods and severely twisted his left ankle. Immediately after the injury he experienced sharp pain in his left foot and ankle and was unable to walk. He was taken to a hospital and diagnosed
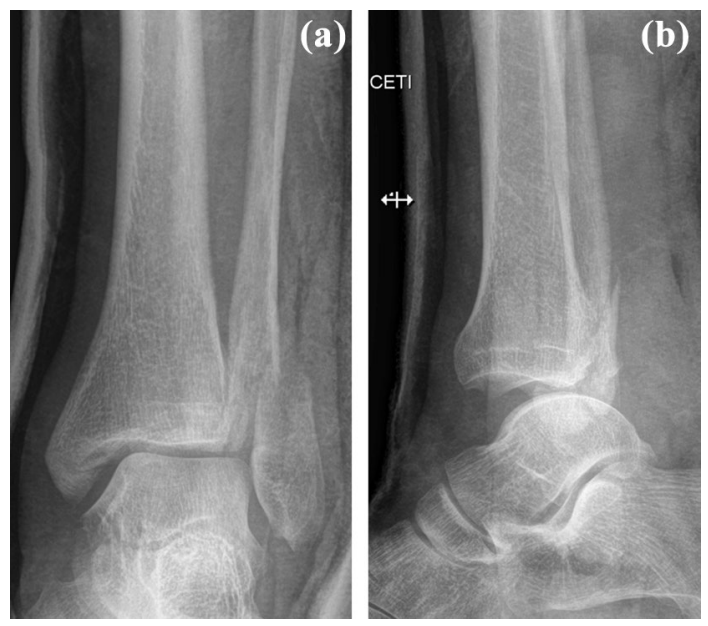

Fig. 1 Initial anteroposterior and lateral radiographs with typical signs of a Bosworth fracture-dislocation: a overlap of the distal tibia and fibula, and $\mathbf{b}$ posterior dislocation of the talus and tibiofibular dissociation with the fibula being displaced posteriorly with a Bosworth fracture of the left ankle $3 \mathrm{~h}$ after the injury. Radiographs showed a Weber type B fracture of the fibula, with a widened medial clear space and a concomitant fracture of the posterior malleolus. The presence of a Bosworth fracture-dislocation was suggested by overlap of the tibia and the proximal fragment of the fibula in the anteroposterior view, posterior subluxation of the talus and tibiofibular dissociation in the lateral view (Fig. 1).

The following attempt at closed reduction under intravenous analgesia failed. The patient was admitted to the hospital and while waiting for reduction under general anesthesia the pain and swelling in his left foot increased and he began to develop paresthesia in the plantar aspect of the left forefoot. Closed reduction under general anesthesia was performed at the night of admission, $8 \mathrm{~h}$ after the injury. According to the treating surgeon, reduction was successful (Fig. 2). Following reduction, the pain subsided as a result of administration of analgesics. On the next morning, $15 \mathrm{~h}$ after the injury, the patient underwent CT examination, including $3 \mathrm{D}$ reconstructions. Although the results confirmed a proper diagnosis of a BF, they also showed failure of reduction. A posterior malleolus (PM) fracture representing type 3 of the Bartoníček-Rammelt classification [12] was detected. The proximal fragment of the fibula was entrapped behind the nondisplaced posterolateral part of the PM fragment (Fig. 3).

Swelling of the lower leg and the foot began to increase over time and blisters appeared around the ankle. A repeat

Table 1 Summary of reported cases with Bosworth fracture-dislocation and compartment syndrome

\begin{tabular}{|c|c|c|c|c|c|}
\hline $\begin{array}{l}\text { First author } \\
\text { (year of publica- } \\
\text { tion) }\end{array}$ & Patient age & Patient sex & Specific remarks on CS and treatment & Fasciotomy & Outcome \\
\hline Szalai (2001) & 28 & f & $\begin{array}{l}3 \text { attempts on closed reduction } \\
\text { Anterior CS }\end{array}$ & Yes & Mild hyperextension of great toe at 3 years \\
\hline Beekman (2003) & 24 & $\mathrm{~m}$ & $\begin{array}{l}1 \text { attempt at closed reduction } \\
\text { CS of } 3 \text { of } 4 \text { lower leg compartments }\end{array}$ & Yes & $\begin{array}{l}\text { Muscle weakness, restricted motion, plan- } \\
\text { tar hypesthesia at } 1 \text { year }\end{array}$ \\
\hline Chung (2004) & 42 & $\mathrm{~m}$ & $\begin{array}{l}1 \text { attempt at closed reduction } \\
\text { Anterior CS after surgery }\end{array}$ & No & $\begin{array}{l}\text { Mild restriction of motion, hypesthesia in } \\
\text { the region of the deep peroneal nerve at } \\
14 \text { months }\end{array}$ \\
\hline Lieder (2014) & 30 & $\mathrm{~m}$ & $\begin{array}{l}\text { Pulseless foot after } 2 \text { attempts on closed } \\
\text { reduction }\end{array}$ & No & Flexion deformity of great toe at 11 months \\
\hline Cho (2019) & N. R & N R & $\begin{array}{l}\text { Average of } 2.2 \text { failed attempts on closed } \\
\text { reduction in } 7 \text { patients }\end{array}$ & N. R & $\begin{array}{l}\text { Poorer overall outcomes with repeated } \\
\text { closed reduction attempts and delayed } \\
\text { surgery }\end{array}$ \\
\hline Ren (2019) & 19 & $\mathrm{~m}$ & $\begin{array}{l}\text { Pulseless foot after } 1 \text { attempt on closed } \\
\text { reduction }\end{array}$ & Yes & Normal function at 18 months \\
\hline Won (2019) & N. R & N. R & $\begin{array}{l}\text { Surgery }>24 \mathrm{~h} \text { after the injury, CS diag- } \\
\text { nosed } 8 \mathrm{~h} \text { after surgery }\end{array}$ & Yes & $\begin{array}{l}\text { Poorer overall outcomes with delayed } \\
\text { surgery }\end{array}$ \\
\hline Won (2019) & N. R & N. R & $\begin{array}{l}\text { Surgery }>24 \mathrm{~h} \text { after the injury, CS diag- } \\
\text { nosed } 8 \mathrm{~h} \text { after surgery }\end{array}$ & Yes & $\begin{array}{l}\text { Poorer overall outcomes with delayed } \\
\text { surgery }\end{array}$ \\
\hline Presented case & 39 & $\mathrm{~m}$ & $\begin{array}{l}2 \text { attempts on closed reduction, persistent } \\
\text { swelling and progressive clawing of the } \\
\text { toes after surgery }\end{array}$ & No & $\begin{array}{l}\text { Limited ankle dorsiflexion, fused first toe, } \\
\text { clawing of lesser toes, plantar hypesthesia } \\
\text { at } 3 \text { years }\end{array}$ \\
\hline
\end{tabular}

$C S$ compartment syndrome, $N$. R. not reported, $m$ male, $f$ female 

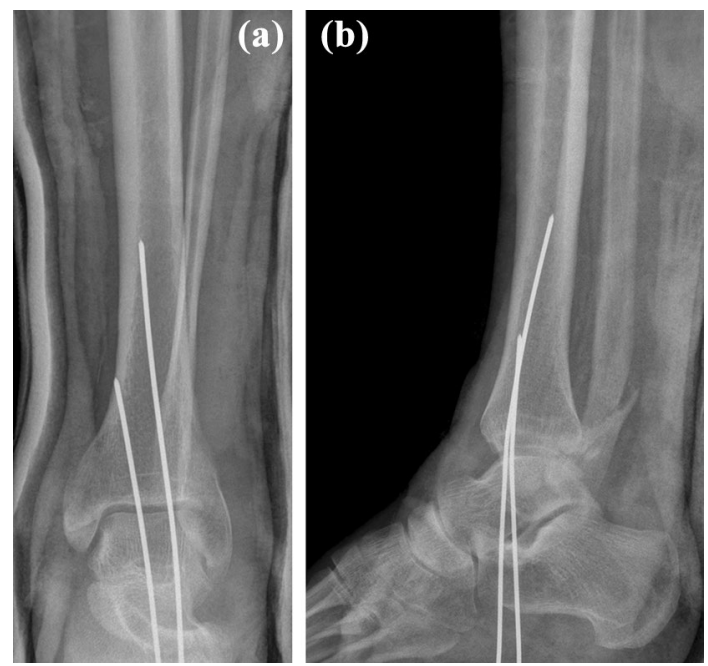

Fig. 2 Radiograph after unsuccessful closed reduction under general anesthesia showing persisting a overlap of the distal tibia and fibula, and $\mathbf{b}$ tibiofibular dissociation

reduction was performed $21 \mathrm{~h}$ after the injury under general anesthesia in the operating room with a bone hook introduced via a short incision over the lateral aspect of distal fibula. Reduction was successful and the ankle joint was then transfixed by 2 Kirschner wires.

The patient was admitted to the hospital. The involved lower limb was elevated and analgesics were administered. Pain, swelling and paresthesia slightly subsided. The condition of soft tissues allowed definite operative treatment 13 days after the injury. First, reduction of the posteromedial fragment of the PM and fixation with 2 pins were performed from a posteromedial approach. In the next step, the distal fibular fracture was reduced via a lateral approach and fixed with two $2.7 \mathrm{~mm}$ lag screws and a $3.5 \mathrm{~mm} 1 / 3$ tubular neutralization plate. The hook test performed at this stage showed instability of the tibiofibular mortise that was subsequently fixed by a $3.5 \mathrm{~mm}$ tibiofibular syndesmotic screw (Fig. 4).

A split lower leg cast was applied for 6 weeks postoperatively. The surgical wounds healed uneventfully. In the postoperative period, the patient showed progressive paresthesia, mainly at the plantar surface of the foot, persisting swelling of the left ankle and development of a clawing of all toes, including a cockup deformity in the great toe. Sensation was diminished in the toes and almost absent in the area of the great toe and the first interdigital web space. The follow-up CT scan 2 months postoperatively documented a nearly anatomic reduction of all fragments, including the distal fibula into the fibular notch (Fig. 5). At that time, the syndesmotic screw was removed.

At 3-month follow-up, a fixed flexion contracture of the great toe was observed without the possibility of passive correction, with ulcerations on the plantar and medial aspect of the great toe and below the first metatarsal head (Fig. 6). A follow-up radiograph proved healing of the fibular and PM fractures. Treatment of the ulceration and rehabilitation
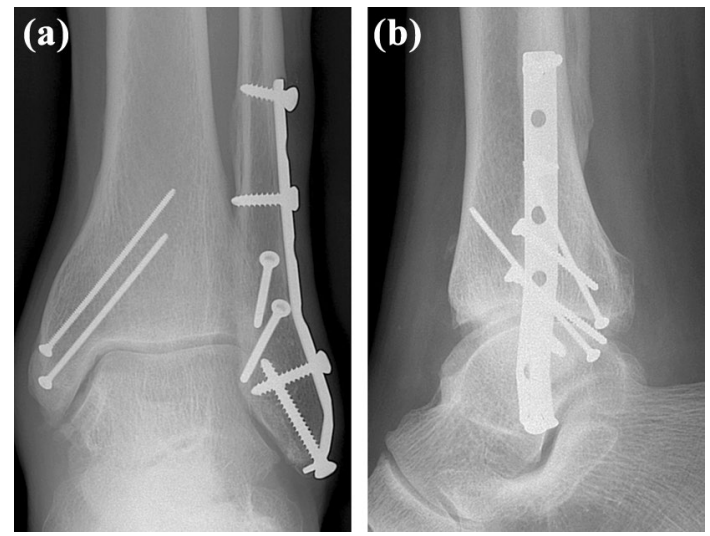

Fig. 4 Postoperative radiographs after open reduction and internal fixation
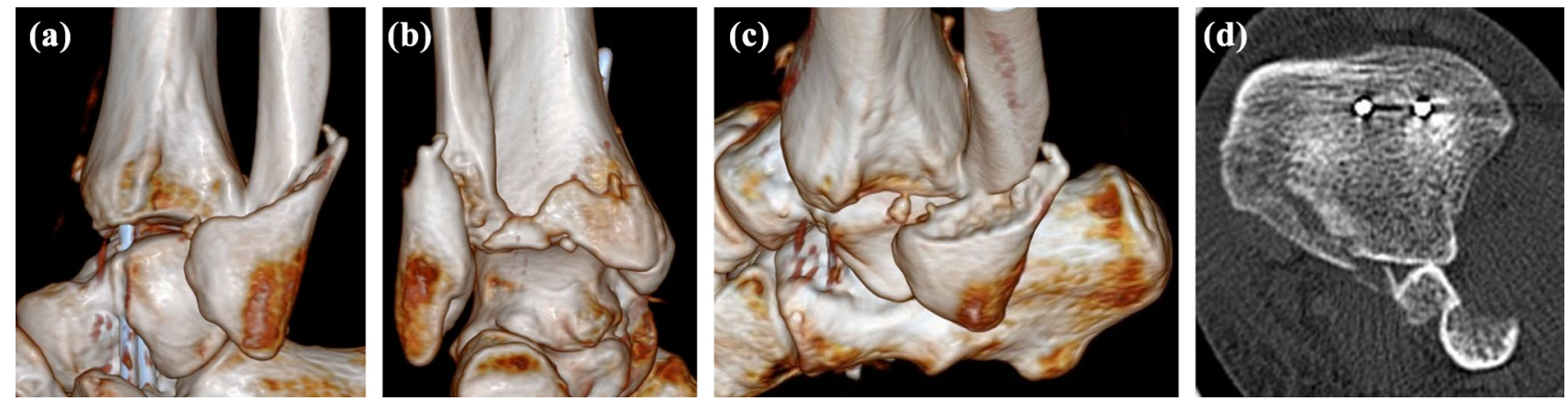

Fig. 3 CT imaging demonstrated posterior displacement of the proximal fibular fragment fracture behind the distal tibia and a minimally displaced fracture of the posterior malleolus (Bartoníček-Rammelt type 3, two-part fracture with extension into the medial malleolus). a lateral 3D CT view; b posterior 3D CT view; c lateral 3D CT view; $\mathbf{d}$ axial CT scan 


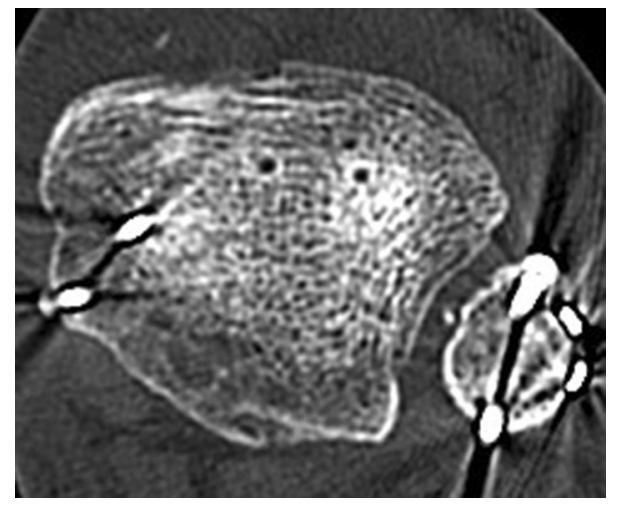

Fig. 5 Postoperative CT control. a axial scan; b frontal scan
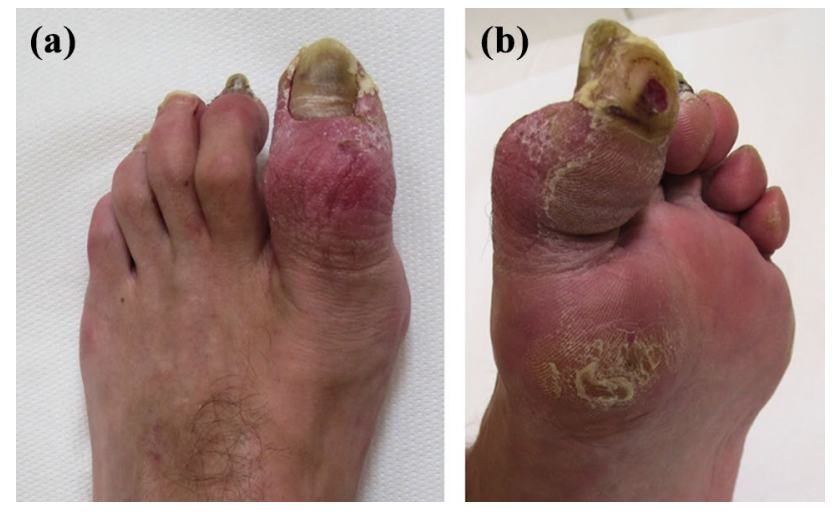

Fig. 6 Clinical image of the formerly injured foot 3 months after surgery demonstrating typical lesions after compartment syndrome

lasted for 6 months. Due to the persisting flexion contracture, a corrective fusion of the interphalangeal joint of the hallux was performed and fixed with two K-wires 18 months after the injury. K-wires were removed after solid bone union, 2 months postoperatively.

At the latest follow-up, 3 years after the injury, the patient was capable of full weight-bearing and jogging. Ankle plantarflexion was normal but dorsiflexion was limited by 10 degrees. The patient complained of persisting decreased sensation on the plantar surface and clawing of the $2^{\text {nd }}$ to $5^{\text {th }}$ toes of the involved foot. The great toe was fused in a plantigrade position and pain-free.

\section{Discussion and literature review}

Compartment syndrome (CS) is an exceedingly rare complication after malleolar fractures typically affecting the deep posterior compartment of the lower leg [6, 13-15]. However, Bosworth fracture-dislocation (BF), a rare variant of an irreducible fracture-dislocation of the ankle, seems to be particularly prone to soft-tissue complications including CS.
The first to report on acute CS complicating a BF were Szalay and Roberts [5]. They described a case of a 28-yearold physician with a typical BF, who underwent three attempts at closed reduction. She was operated on $24 \mathrm{~h}$ after the injury. Approximately $8 \mathrm{~h}$ postoperatively, an anterior compartment syndrome of the lower leg began to develop. The patient underwent fasciotomy of all four compartments. Three years after surgery the patient had a mild residual hyperextension deformity of the great toe.

Beekman and Watson [6] reported on a 24-year-old patient who was sent home after a failed closed reduction attempt of the BF despite substantial soft-tissue swelling and returned to the emergency room $12 \mathrm{~h}$ later with already decreased plantar sensation and pain on passive stretch of the great toe. Multiple stick measurements revealed a CS with pathologic pressures in 3 of the 4 lower leg compartments and emergency fasciotomy of all 4 compartments was carried out. Following open reduction and internal fixation, the patient underwent two more surgical revisions with debridement of necrotic muscle from the anterior, lateral and deep posterior compartments. At one year, the patient still displayed a mildly antalgic gait with decreased dorsiflexion and plantar flexion of the ankle, continuing weakness of the toe flexors and extensors, and residual mild paresthesia on the plantar surface of the foot.

Chung [7] described a typical Bosworth fracture, i.e., a Weber type B fibula fracture and rupture of the deltoid ligament, with an anterior CS of the lower leg developing postoperatively and mild symptoms persisting at 14 months.

The patient reported by Lieder [8] underwent two unsuccessful closed reductions in the emergency department. The foot was noted to be cool and pulseless. CT angiogram demonstrated tapering of the flow of the anterior tibial, posterior tibial and peroneal arteries at the distal third of the lower leg and no visualization of the dorsalis pedis or plantar arteries. After urgent surgery, the patient was found to have an intact dorsalis pedis artery and posterior Doppler signals. At 11 months postoperatively, the patient reported restoration of sensation in his foot, however, a flexion deformity of the great toe persisted. Cho et al. [9], in a group of $16 \mathrm{BFs}$, found one case with CS, but did not specify details. In their series, the authors found the time interval to surgery and the number of manual reduction attempts to be negatively correlated with functional outcome.

Ren et al. [10] described a case of a 19-year-old patient who suffered a trimalleolar fracture of the ankle with a severe fixed external rotation deformity of the foot and skin tenting. The pulses of the dorsalis pedis and posterior tibial arteries could not be detected. The first attempt on closed reduction in the emergency room was unsuccessful. Radiographs showed a Weber type B fracture of the ankle and a fracture of the medial malleolus. CT scan proved a fracture of PM (Bartoníček Rammelt type 3), displacement of the 
proximal fibular fragment between the posterior aspect of distal tibia and the displaced PM. Reduction and internal fixation of the fibula and PM were performed via a posterolateral approach. One day after the operation, the patient developed postischemic CS, requiring fasciotomy. Eighteen months after the injury the function of the ankle was restored to normal and the patient had no subjective complaints.

Won et al. [11] analyzed a group of $51 \mathrm{BFs}$, which they divided into two groups. Group A included 36 patients operated on $24 \mathrm{~h}$ and later post-injury and group B comprised 15 patients operated on within $24 \mathrm{~h}$. In group A, the authors found 2 cases of CS, requiring fasciotomy. An impending CS with BF was described by Ellanti et al. [16] and Yeoh et al. [17]. The complication was avoided by a timely open reduction in both cases and delayed wound closure in one case [17].

Overall, including the case presented here, 9 cases of compartment syndrome [5-11] have been described in the literature (Table 1). This results in a calculated prevalence of $5.4 \%$ out of 167 reported Bosworth fractures (Weber B and C types) [3, 4, 9-11, 18, 19]. Given the extreme paucity of $\mathrm{CS}$ in malleolar fractures, this is a high prevalence.

Besides CS, several reports on BF mention circulatory deficits resulting from the marked dislocation of the ankle. Fahey et al. [20], in 1956, described cyanosis, numbness and decreased temperature in two patients treated operatively for BF after repeated attempts at closed reduction had failed. The cases of Lieder et al. [8] and Ren et al. [10] described above could be interpreted as a postischemic CS following a circulatory deficit of the lower leg [21]. Further soft tissue complications associated with BF include skin necrosis and ankle stiffness particularly after delayed reduction $[2,3,9$, $19,22]$.

The presented cases share certain common features. The first of them is a marked foot deformity upon admission, i.e., severe external rotation of the foot and posterior dislocation of the talus to the tibia often associated with skin tenting and circulatory deficits $[8,10,20]$. In all cases described in detail, there were repeated unsuccessful attempts at closed reduction that adds to the soft tissue damage $[5-8,20]$.

Another important prognostic factor is the interval between the injury and a successful (open) reduction. Significantly inferior results have been reported if reduction was delayed for more than $24 \mathrm{~h}[5,6,11]$. Persistent dislocation increases the strain on the soft tissues thus potentially increasing the risk for soft tissue-related complications like skin necrosis, neurovascular damage, and CS. However, CS may also develop after a successful reduction [7, 8]. Furthermore, postischemic compartment syndrome may develop after successful revascularization [21] or restoring circulation through reduction as in two of the reported cases $[8,10]$.

In our case, the diagnosis of a BF was established properly, but the risk of CS development was underestimated.
Furthermore, the quality of reduction performed under general anesthesia in the operating theatre was poor. In the further course, the development of CS was neglected, when analgesics partly obscured the typical pain. Diagnosis of a CS is primarily established clinically. The importance of clinical signs like increasing swelling and pain despite rest, cooling, elevation and pain medication, loss of skin wrinkling, blister formation, and pain on passive toe movement cannot be overestimated. Because the deep posterior compartment of the lower leg has a direct connection to the deep central (calcaneal) compartment of the foot, concurrent CS of the lower leg and foot also has to be considered [23, 24].

Early fasciotomy is warranted to avoid the late sequelae of CS of the lower leg and foot like rigid claw or hammertoe formation, cavus foot, equinovarus contracture, chronic pain or dysesthesia and callus or ulcer formation at the foot $[21,23,24]$. Some of these sequelae have been reported in the present case as well in the literature $[5,6,8]$. These deformities may warrant secondary corrective surgery and persistent functional deficits are likely to develop as muscle contracture resulting from CS is irreversible [21, 25, 26].

\section{Conclusions}

While compartment syndrome is exceedingly rare after malleolar fractures it appears to be a relatively common complication of the Bosworth fracture-dislocation. This complication should be taken into account already during the initial examination of the patient. The risk of CS is increased with extreme external rotation of the foot, repeated attempts on closed reduction and delayed successful reduction of the ankle. The typical signs include massive swelling of the lower leg (and foot), blister formation, increasing pain despite rest, cooling and elevation, with paresthesia or loss of sensation already being a late sign. Radiographs show tibiofibular overlap in the anteroposterior view and tibiofibular diastasis and posterior displacement of the talus in lateral view. CT imaging should be performed in all suspected BFs as they will regularly reveal concomitant injuries like posterior malleolar fractures.

After confirmation of the diagnosis of a BF, it is essential to perform reduction as soon as possible. Closed reduction is almost always unsuccessful and repeated attempts will inevitably increase the soft tissue damage. Reduction must therefore always be performed under general or spinal anesthesia in an operating theatre. If immediate open reduction and internal fixation is impossible due to poor condition of the soft tissues or critical overall status of the patient, it is necessary to perform reduction of the displaced fibula percutaneously with a bone hook from a short incision above the fibula. Dermatofasciotomy must be performed if marked soft tissue swelling of the lower leg persists after 
successful reduction. The risk of a postischemic CS should be considered after a successful reduction and restoration of an initially compromised circulation. Therefore, continued peripheral anesthesia is contraindicated in these patients. Delayed recognition of CS regularly leads to persistent functional limitations.

Acknowledgements This study was supported by the Ministry of Defense of the Czech Republic, Grant No. IP DZRVO MO1012. The authors would like to thank Professor Chang-Wug Oh, Daegu, Republic of Korea, for his help with translation of the Korean literature.

Funding Open Access funding enabled and organized by Projekt DEAL. This study was supported by the Ministry of Defense of the Czech Republic, Grant No. IP DZRVO MO1012

\section{Compliance with ethical standards}

Conflict of interest Stefan Rammelt is a paid consultant for KLS Martin. All authors recieved travel support by the AO Foundation for meetings and courses. No conflict of interest resulted for the submitted work.

Ethical appproval This article does not contain any studies with human participants or animals performed by any of the authors.

Informed consent The patient was informed that data pertaining to his case were considered for submission as an anonymous case report and he consented.

Open Access This article is licensed under a Creative Commons Attribution 4.0 International License, which permits use, sharing, adaptation, distribution and reproduction in any medium or format, as long as you give appropriate credit to the original author(s) and the source, provide a link to the Creative Commons licence, and indicate if changes were made. The images or other third party material in this article are included in the article's Creative Commons licence, unless indicated otherwise in a credit line to the material. If material is not included in the article's Creative Commons licence and your intended use is not permitted by statutory regulation or exceeds the permitted use, you will need to obtain permission directly from the copyright holder. To view a copy of this licence, visit http://creativecommons.org/licenses/by/4.0/.

\section{References}

1. Bosworth DM (1947) Fracture-dislocation of the ankle with fixed displacement of the fibula behind the tibia. J Bone Joint Surg 29:130-135

2. Bartoníček J, Frič V, Svatoš F, Luňáček L (2007) Bosworth-type fibular entrapment injuries of the ankle- the Bosworth lesion. A report of 6 cases and literature review. J Orthop Trauma 21:710717. https://doi.org/10.1097/BOT.0b013e31815affb7

3. Bartoníček J, Kostlivý K, Rammelt S (2017) Bosworth fracture. A report of two atypical cases and literature review of 108 cases. FussSprungg 15:126-137. https://doi.org/10.1016/j.fuspr u.2017.02.002

4. Kostlivý K, Bartoníček J, Rammelt S (2020) Posterior malleolus fractures in Bosworth fracture-dislocations. A combination not to be missed. Injury 51:537-541. https://doi.org/10.1016/j.injur y.2019.10.088
5. Szalay Y, Roberts JB (2001) Compartment syndrome after Bosworth fracture-dislocation of the ankle: a case report. J Orthop Trauma 15:301-303

6. Beekman R, Watson JT (2003) Bosworth fracture-dislocation and resultant compartment syndrome. A case report. J Bone Joint Surg Am 85:2211-2214. https://doi.org/10.2106/00004623-20031 1000-00025

7. Chung HJ, Park SL, Choi YS (2004) Anterior compartment syndrome after surgery of Bosworth fracture-dislocation of the ankle-a case report. J Korean Foot Ankle Soc 8:221-223

8. Lieder C, Riff A, Johnston P, Szatkowski J (2014) A 30-yearold soccer player presents with a paniful left ankle. Orthopaedics Today 111:1-5

9. Cho BK, Choi SM, Shin YD (2019) Prognostic factors for intermediate-term clinical outcomes following Bosworth fractures of the ankle joint. Foot Ankle Surg 25:601-607. https://doi. org/10.1016/j.fas.2018.05.005

10. Ren W, Hu YC, Lu JK (2019) Rare variants of Bosworth fracturedislocation: Bosworth fracture-dislocation with medial malleolus adduction type fracture. Chin J Traumatol 22:120-124. https://doi. org/10.1016/j.cjtee.2018.12.001

11. Won Y, Lee GS, Hwang JM, Park IY, Song JH, Kang C, Hwang DS (2019) Improved functional outcome after early reduction in Bosworth fracture-dislocation. Foot Ankle Surg 25:798-803. https ://doi.org/10.1016/j.fas.2018.10.007

12. Bartoníček J, Rammelt $\mathrm{S}$, Kostlivý K, Vaněček V, Klika D, Trešl I (2015) Anatomy and classification of the posterior tibial fragment in ankle fractures. Arch Orthop Trauma Surg 135:506-516. https ://doi.org/10.1007/s00402-015-2171-4

13. Horne $G$ (1984) Pes cavovarus following ankle fracture. A case report. Clin Orthop Relat Res 184:249-250

14. Ashworth MJ, Patel N (1998) Compartment syndrome following ankle fracture-dislocation: a case report. J Orthop Trauma 12(1):67-68

15. Joseph J, Giannoudis PV, Hinsche A, Cohen A, Matthews SJ, Smith RM (2000) Compartment syndrome following isolated ankle fracture. Int Orthop 24(3):173-175

16. Ellanti P, Hammad Y, Grieve PP (2013) Acutely irreducible ankle fracture dislocation: a report of a Bosworth fracture and its management. J Emerg Med 44:e349-e352

17. Yeoh CSN, Tan GMJ (2013) Bosworth fracture-dislocation of the ankle: a case report. J Orthop Surg 21:249-252

18. Hasler J, Antoniadis A, Gkagkalis G, Flury A, Moerenhout K (2019) The irreducible ankle dislocation: beware of the Bosworth injury. Unfallchirurg 122:992-996. https://doi.org/10.1007/s0011 3-019-00725-1

19. Fan J, Michelin RM, Jenkins R, Hwang M, French M (2020) A novel technique for a successful closed reduction of a Bosworth fracture-dislocation of the ankle. Cureus 12:e6632. https://doi. org/10.7759/cureus.6632

20. Fahey JJ, Schlenker LT, Stauffer RC (1956) Fracture dislocation of the ankle with fixed displacement of the fibula behind the tibia. Am J Radiol 76:1102-1113

21. Rammelt S, Zwipp H (2008) Reconstructive surgery after compartment syndrome of the lower leg and foot. Eur J Trauma 34:237-248

22. Lui TH, Chan KB, Kong CC, Ngai WK (2008) Ankle stiffness after Bosworth fracture dislocation of the ankle. Arch Orthop Trauma Surg 128(1):49-53

23. Manoli A 2nd, Fakhouri AJ, Weber TG (1993) Concurrent compartment syndromes of the foot and leg. Foot Ankle 14(6):339-342

24. Sands AK, Rammelt S, Manoli A (2015) Foot compartment syndrome: a clinical review. FussSprungg 13:11-21 
25. Rammelt S, Zwipp H, Hansen ST (2019) Posttraumatic reconstruction of the foot and ankle. In: Browner BD, Jupiter JB, Krettek C, Anderson PA (eds) Skeletal Trauma, 6th edn. Elsevier Saunders, Philadelphia, pp 2641-2690

26. Zibis A, Varitimidis S, Fyllos A, Raoulis V, Karachalios T, Malizos K (2020) An observational study of complications in patients with established multiple compartments syndrome of the leg.
Arch Orthop Trauma Surg. https://doi.org/10.1007/s00402-02003488-2

Publisher's Note Springer Nature remains neutral with regard to jurisdictional claims in published maps and institutional affiliations. 